\title{
Correspondence
}

\section{Consultant psychiatrists' caseload}

Sir: The analysis of the consultant psychiatrist's caseload by Fagin et al (Psychiatric Bulletin, September 1995, 19, 532-535) is commendable and relevant to advances in the costing of care and future purchasing plans.

The article nevertheless included several common misconceptions concerning standard NHS consultant contracts which I wish to draw attention to.

While consultants have a professional contract which requires their continuing responsibility for the care of their patients, the available guidance defines this commitment as ten and not eleven sessions ( 3.5 hours each, adding up to 35 hours a week). There is no difference in the sessional commitments of whole-time and maximum parttime consultants, though the latter group is paid $1 / 11$ th less in return for unrestricted private earnings.

Consultants can and should include their travelling time between various locations of work in their calculation of their sessional commitments. Maximum part-time consultants should also be able to include an allowance for their home-base travel.

Consultant on-call duties are not additional to their sessional commitment but constitute part of it.

And finally, consultants with standard contracts may not be able to include their court or forensic work in the calculation of their NHS duties, especially when this work attracts a separate fee.

\section{S. ElAmeER}

St David's Hospital, Carmarthen, Dyfed SA31 3HB

\section{Improper terminology}

Sir: I was saddened to see the term 'dements' used as a title of a letter in your journal (Psychiatric Bulletin, November 1995, 19, 704705). This is certainly a dehumanising derogatory term. I doubt terms such as 'schizos' or 'psychos' would be acceptable for printing, so why 'dements'? We as a profession are striving to remove the stigmatisation of those with mental health problems, to see the whole person not just the illness. Such language in such a journal hampers our efforts. I hope it was an oversight.

S. MANCHIP

Department of Old Age Psychiatry.

Victoria Hospital, Okus Road,

Swindon SN1 4JU

It was.

THE EDITOR

\section{Mental Health Task Force Support Group}

Sir: Drs Reid and Turner are obviously very adept at reading between the lines. Their interpretation of the work that John Wattis and I reported (Psychiatric Bulletin, April 1995, 19, 250-251) is substantially correct. Both John Wattis and I had precisely the impression which Reid and Turner obtained from our report of the work which we had to carry out on behalf of the College in order to allow Council to remain informed of the work of the Mental Health Task Force. I shall be as interested as they will be if anyone can identify any "tangible benefits of the Mental Health Task Force".

\section{CHRIS THOMPSON}

Registrar, The Royal College of Psychiatrists, London

\section{Social deprivation, ethnicity and violent incidents on acute psychiatric wards}

Sir: We were interested to read the paper by Sheehan et al (Psychiatric Bulletin, October 1995, 19, 597-599). We investigated a slightly different but similar relationship between the level of violence on acute psychiatric wards in two health districts, Nottingham and Lincoln, and were able to establish a relationship between the levels of violence in both districts with that of the general population (Walker \& Caplan, 1993). A significant area of difference was that we found a higher incidence of violence in detained patients whereas the majority of Sheehan et al's perpetrators were informal. However, given the broadly similar message which can be drawn from both papers it should be possible to estimate the expected level of 